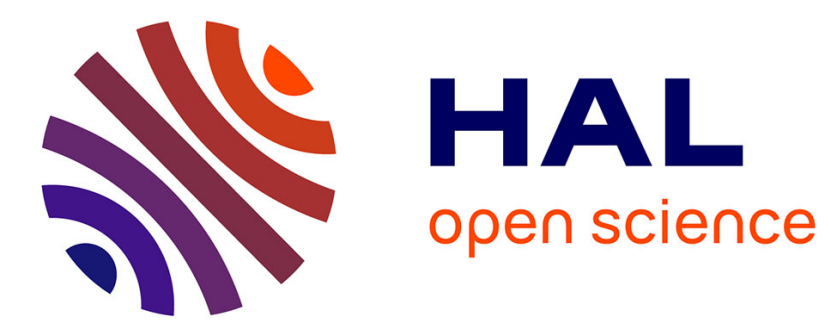

\title{
A Spectro-gestural-morphological Analysis of a Musical-tactile score
}

Eric Maestri

\section{To cite this version:}

Eric Maestri. A Spectro-gestural-morphological Analysis of a Musical-tactile score. Computational Aesthetic, In press. halshs-01644111

\section{HAL Id: halshs-01644111 https://shs.hal.science/halshs-01644111}

Submitted on 14 Mar 2018

HAL is a multi-disciplinary open access archive for the deposit and dissemination of scientific research documents, whether they are published or not. The documents may come from teaching and research institutions in France or abroad, or from public or private research centers.
L'archive ouverte pluridisciplinaire HAL, est destinée au dépôt et à la diffusion de documents scientifiques de niveau recherche, publiés ou non, émanant des établissements d'enseignement et de recherche français ou étrangers, des laboratoires publics ou privés. 


\title{
A Spectro-gestural-morphological Analysis of a Musical-tactile score
}

\author{
Eric Maestri \\ LabEX GREAM, University of Strasbourg \\ CIEREC, University “Jean Monnet” - Saint-Etienne
}

\begin{abstract}
In the following article the author will compare a musical and a tactile score in the specific case study represented by Rieko Suzuki's tactile score transcription of Friedrich Chopin's posthume Nocturne $\mathrm{n}^{\circ} 20$ in $C$ sharp minor. In the intention of the author this comparison will show its correlations between sound, movement and musical representation and will highlights the common features of musical and the tactile notation. To conduct this analysis it will be compared the movement indicated by the musical score and the ones prescribed by the tactile score applying and expanding Denis Smalley's spectromorphological analysis towards a spectro-gestural-morphological analysis. For this reason the author invite the reader to refer to Smalley's explanation of spectromorphological analysis (Smalley 1997). This research must be considered as a contribution related with the actual debate on sonification (Hermann, Hunt, Neuhoff 2011) musical cognition (Launay 2015, Schaefer 2015) and mediation (Leman 2007) and will implicitly suggest a possible artistic application of tactile scores as basis of new compositional techniques.
\end{abstract}

\section{Tactile scores}

Tactile scores were created by Rieko Suzuki in order to describe and design tactile sense. Those scores are used to notate actions oriented to massage and to transmit those informations in order to create a repertory of "massage pieces". They are used to transcribe musical works in massage's scores (in the case of tactile scores based on preexisting music), to compose music, to develop emotional engineering and haptic design (Suzuki, Suzuki 2014). Tactile scores are the result of a long process of elaboration based on trials and errors that brings to define the most important massage's parameters: dimension, pressure and speed. During this period, in which Rieko Suzuki tried new massage's strategy with her customers, tactile scores became more detailed, from hieroglyphic-like inscription to diastematic notation, and progressively reveal common features with musical scores expressing a certain proximity between tactile and musical experience. In fact, as Rieko Suzuki wrote:

[...] counts and rhythm are important in tactile perception; a single circular stroke could not be distinguished from a mere rubbing, while more than double strokes would be recognized as massage. By giving rhythm on a tactile sense, we can create "impressions"; a rhythm of touching gives a "theme" on the impression provoked by tactile sense, where the theme is the expression through tactile sense such as small-large, fast-slow, line-curve and so on; in a sequence of massage strokes starts from small circles then moves to large circles and small circles again, à subject would feel small and large (Suzuki, 
Tactile scores notate gestures characterized by specific movements of the hand on the face; they are based on profiles, speed and pressure changing. Thus, the succession of those tactile objects defines a temporal experience that provoke complex sensations and feelings:

We suppose that our image caused by tactile sense emerges from the temporal relationship; we always compare the tactile sense in the past and at the present. If we touch something hard, and then touch something harder, we regard the former as softer (Suzuki, Suzuki 2014: 32)

The development of tactile scores points common experiential feature with musical scores. In fact, as tactile scores' case, the development of musical notation reveals, during its long process, the arousal of the awareness of the substantial temporal aspect of musical syntax. As musical scores, tactile scores are based on objects that constitute an alphabet. They are built of a trials and errors process that is described by the ecological action-perception cycle model. Tactile and musical scores are characterized by a similar graphical representation strategy, that is in both cases diastematic. Tactile scores provide an example of multi-modal representation and offer, in author's opinion, an important case study that gives the possibility, as Laban notation, to compare actions related to sound perception. In fact, tactile scores, that recode acoustic in tactile experience, provide a notation example based on a similar functionality of gesture prescription. As in music, in which notation doesn't directly prescribe sounds but mediately towards gestures, tactile scores, are based on gesture prescription that mediate the tactile experience. Those scores reveals "basic schemata of perception" (Godøy 2006)in which gesture is the multi-modal central element. This parallelism will be analyzed towards Pierre Schaeffer's notion of sonorous object (Schaeffer 1966: 268). Thus, in the following of this research, the author will try to propose an enlargement of the notion of sonorous object into a broader one of sonorous-gestural object that will constitute the basic notion of a spectro-gesturalmorphological analysis.

\section{Gestural-sonorous Objects and Spectromorphology}

In order to analyse the relationship between the musical and the tactile score we propose to begin our study from Pierre Schaeffer's notion of sonorous object. The brief analysis of this concept will show the presence of gestural metaphors in sonorous objects qualification that link, through gestures tactile and acoustic experience. The sonorous objects are sound fragments extrapolated from the causal sound event that produce it. They could be defined by a random cut (version) or an intentional one based on the stress-articulation principle (theme) (Schaeffer 1966: 390-92). Without entering in the important debate around this crucial notion, the author suggest that it allows to define the units that compose the auditory stream, offering the first attempt to define the auditory experience from a cognitive point of view, that is nowadays widely accepted. Sonorous objects provide

the means for capturing and reflecting on the otherwise ephemeral or transitory nature of musical sound, i.e. allowed what we could call a mental recoding of sound to more stable images in our minds. 
(Godøy 2006: 149)

Actually, they provide a powerful analytical (and compositional) means, capable to recode the auditory experience in multi-modal images. As stated by Godøy:

Schaeffer did make use of a number of gestural concepts and metaphors in qualifying sonorous objects. Going a bit deeper into this, I shall argue that Schaeffer's use of gestural concepts and metaphors can be related to the idea of so-called embodied cognition, meaning that virtually all domains of human perception and thinking, even seemingly abstract domains, are related to images of movement (Gallese and Lakoff 2005). For these reasons, I shall introduce the concept of gestural- sonorous objects in this paper, meaning an extension of Schaeffer's thoughts on exploring sonorous objects to also include the exploration of gestures associated with the various sonorous objects (Godøy 2006: 150).

Godoy hypothesizes that the strategy of segmentation applied for the analyses of sonorous objects could be applied in the analysis of gestural objects on the basis of a fundamental cognitive schemata:

$[\ldots]$ there is a continuos process of mentally tracing sound in music (and in musical imagery as well), i.e. mentally tracing the onsets, contours, textures, envelopes, etc., by hands, fingers, arms, or other effectors, when we listen to, or merely imagine, music. This means that from continuous listening and continuous sound-tracing, we actually recode musical sound into multimodal gestural-sonorous images based on biomechanical constraints (what we imagine our bodies can do), hence into images that also have visual (kinematic) and motor (effort, proprioceptive, etc.) components. Furthermore, this recoding is conceived of as a bidirectional process, i.e. that gestural images may engender sonorous images as well (Godøy 2006: 149-150).

Starting from this assumption, largely debated today, our analysis aims to dissect the relationship between the sound movements and the massage movements expressed in the tactile score. More precisely, we will analyze the sound-tracing gestures (Godoy 2006: 154) in order to highlight the traces in the gesture of the deeper cognitive structure expressed in notation. This notion of gesturalsonorous objects will be used as starting point of an unorthodox application of the spectromophological approach proposed by Denis Smalley that will be used as a methodological basis for the analysis of gestural-sonorous objects. This methodology is defined by Denis Smalley as

$[\ldots]$ tools for describing and analysing the listening experience. The two parts of the term refer to the interaction between sound spectra (spectro-) and the ways they change and are shaped through time (-morphology). The spectro- cannot exist without the -morphology and vice versa: some- thing has to be shaped, and a shape must have sonic content. Although spectral content and temporal shaping are indissolubly linked, we need conceptually to be able to separate them for discursive purposes - we cannot in the same breath describe what is shaped and the shapes themselves. The term may be rather jargonistic and it is perhaps an ungainly word, but I have not managed to invent an alternative which encapsulates the interactive components so accurately. Each component of the term belongs to other disciplines (visual, linguistic, biological, geological), which is fitting since musical experience radiates across disciplines. But the combination is unique: in music we often need words which are invented specially for defining sonic phenomena. A spectromorphological approach sets out spectral and morphological models and processes, and provides a framework for understanding structural relations and behaviours as experienced in the temporal flux of the music. (Smalley 1997: 107)

Spectromorhology, that at a first glance seams a re-proposition of Schaeffer's typo-morphology, is, on the contrary, based on an opposite interpretation of the notion of sonorous object, that is linked to the referential activity of the listener, that is considered as central in the listening strategy. In fact 
this methodology define the auditory stream cognition as rooted in listener's referential gestural experience, defined as sound source bonding. In this sense Smalley suggest that sound perception is necessary linked with agency perception and, thus, in author's opinion, with the gestural memory that collect tactile and acoustic experience. This approach evoke the cognitive notion of sound imagery (Lunay 2015), implicitly linking this research to the more recent developments in cognitive sciences. In Smalley's words:

One might think that in more 'abstract' instrumental music, source bondings do not exist, but they are there in force, revealed through gesture and other physical activity involved in sound-making. The bonding of instrumental activity to human gesture is somewhat ignored not only because it is invariably expected in music, but also possibly because much music study has tended to concentrate on music writing (notation), theory and analysis, which tend to distance a work from the gestural activity of its performance. Vocal presence, whether revealed through stylized singing or direct utterance, has direct human, physical, and therefore psychological links. In electroacoustic music the instrumental and vocal are included, but unlike traditional music where instrumental and vocal presence are assumed and known in advance, in acousmatic electroacoustic music they are both to be encountered (unexpectedly) and inferred. Electroacoustic music, then, subsumes instrumental and vocal experience: instrumental and vocal resources are a 'subset' of the wide-open sound world which is electroacoustic music's territory. (Smalley 1997: 111)

Smalley links sound and source perception proposing a methodology based on the constitutive distinction of gesture and texture that are distinguished on the basis of listener's proprioceptive experience, that is provoked by the sonic traces of the human agency behind sound sources.

A human agent produces spectromorphologies via the motion of gesture, using the sense of touch or an implement to apply energy to a sounding body. A gesture is therefore an energy-motion trajectory which excites the sounding body, creating spectromorphological life. From the viewpoint of both agent and watching listener, the musical gesture-process is tactile and visual as well as aural. Moreover, it is proprioceptive: that is, it is concerned with the tension and relaxation of muscles, with effort and resistance. In this way sound-making is linked to more comprehensive sensorimotor and psychological experience. We should not think of the gesture process only in the one direction of cause-source-spectromorphology, but also in reverse - spectromorphologysource-cause. When we hear spectromorphologies we detect the humanity behind them by deducing gestural activity, referring back through gesture to proprioceptive and psychological experience in general. Everyone uses this spectromorphological referral process when listening to recordings of instrumental music. Not only do we listen to the music, but we also decode the human activity behind the spectromorphologies through which we automatically gain a wealth of psycho-physical information. [...] The basic gesture of traditional instrumental music produces the note. In tonal music notes form a consistent low-level unit, and are grouped into higher levelled gestural contours, into phraseological styles, which traditionally have been based on breath- groups. Singers and wind-players, after all, have to breathe. In electroacoustic music the scale of gestural impetus is also variable, from the smallest attack-morphology to the broad sweep of a much longer gesture, continuous in its motion and flexible in its pacing. The notion of gesture as a forming principle is concerned with propelling time forwards, with moving away from one goal towards the next goal in the structure - the energy of motion expressed through spectral and morphological change. Gestural music, then, is governed by a sense of forward motion, of linearity, of narrativity. The energy-motion trajectory of gesture is therefore not only the history of an individual event, but can also be an approach to the psychology of time. If gestures are weak, if they become too stretched out in time, or if they become too slowly evolving, we lose the human physicality. We seem to cross a blurred border between events on a human scale and events on a more worldly, environmental scale. At the same time there is a change of listening focus- the slower the directed, gestural impetus, the more the ear seeks to concentrate on inner details (insofar as they exist). A music which is primarily textural, then, concentrates on internal activity at the expense of forward impetus. (Smalley 1997: 113-14) 
Sonorous and gestural objects emerge as expressions of a fundamental, "hidden", anthropological schema. The perception of gestural of sound components allow perceivers to understand the sound source quality (the "facture" in Pierre Schaeffer's terminology) and the agency (the "agent"). This approach implicitly criticizes the notion of reduced listening that defines, in the terms proposed by Pierre Schaeffer, the very essence of sonorous objects: they are the correlative of reduced listening, that is conceived as a listening strategy based on the abstraction of the cause and sense from sonorous objects. On the opposite, Denis Smalley proposed an embodied listening, rooted in listener's cognitive experience.

Our analysis will try to highlight some aspects related with this complex relationship between sounds and gestures. It will concerns mainly the profile of the musical object and will mainly concern the global external morphology of them. We will use the definition of spectromorphological movement to compare the musical object movement in register (melodic profile) and in dynamic (dynamic profile); the tactile gestures will be analyzed via the movement of the hand, the movement of the hand on the face and the pressure. The movements of the melodic and the dynamic profile are considered traditionally: ascending means from a lower to a higher register (melodic profile), from weak to strong (dynamic profile). For the movements of the hand (on the face, of the hand, of hand's pressure) ascending means from the bottom to the upper part of the face, i.e. from the chin to the forehead, from the palm to the fingertips, from a weak to a strong pressure. Descending is defined in opposition. The author hope that those definitions will allow the reader to follow and verify the analysis.

\section{Analysis}

In the next paragraph the author will analyze the first phrase of the second section of Chopin's Nocturne in $C$ sharp minor (opus posthume) that is completely transcoded in a tactile score (the bottom part of the score, fig.). This musical phrase is played in the middle register and presents a very light and melodic atmosphere, in opposition with the most dark character of the first section. Before, we invite the reader to read Suzuki's article about tactile scores in which she will find tactile score's symbols and meaning (Suzuki, Suzuki 2014: 21-26). The first phrase of this second section is characterized by four sub-phrases that correspond to the bars. The next analysis will be based on the definition and comparison of the following gestural and sonorous movement typologies: melodic profile (the movement towards the registers); dynamic profile (movement of the dynamic); hand movement (the movement of the hand on its part); face movement (the movement of the hands on the face); pressure (hand's pressure).

In the first bar the musical unit is based on a melodic movement from $\mathrm{E}_{4}$ to $\mathrm{D}_{5}$ and back to $\mathrm{H}_{4}$, creating a reciprocal-parabola profile, characterized, dynamically, by a crescendo and diminuendo (reciprocal-parabola). This profile is defined by two types of motion. The first one is unidirectionnal- 


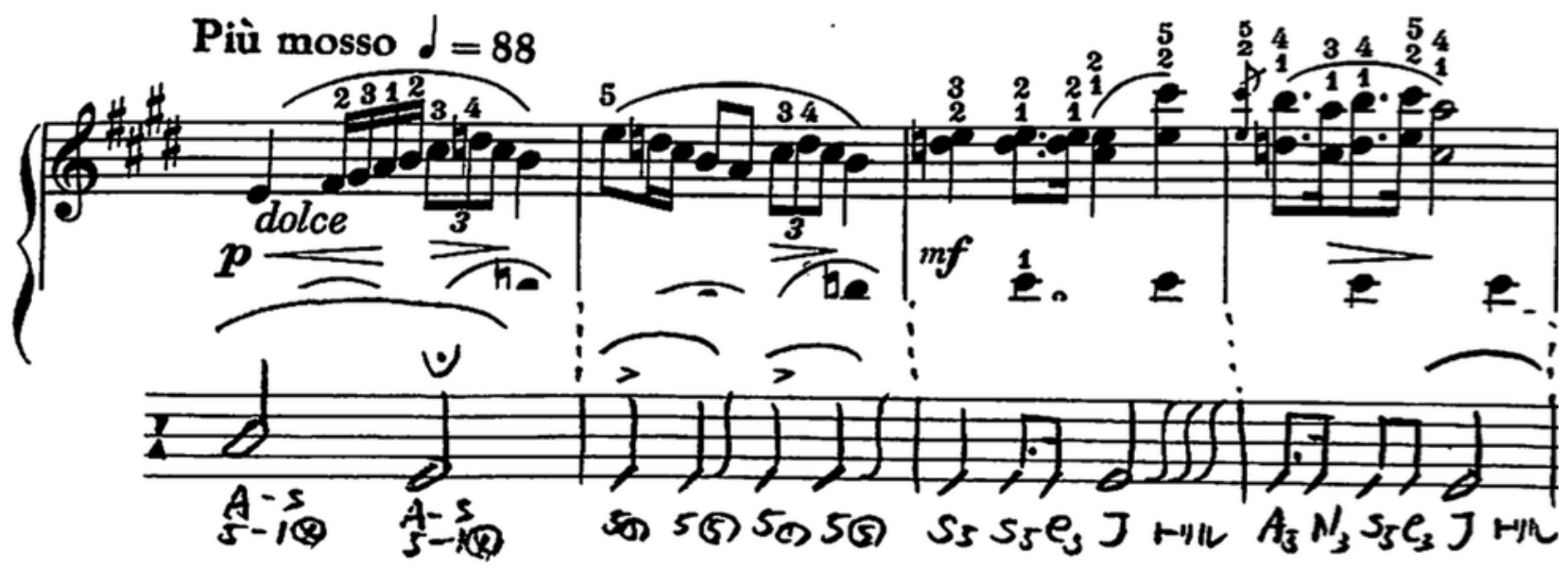

ascending (from $\mathrm{E}_{4}$ to $\mathrm{D}_{5}$ ); the second one is cyclic/centric (around the $\mathrm{C}_{5}$ ) and slightly descending to the final note. Concerning the movement of the hand the correlated tactile score indicates a movement from the palm progressively going to the fingertip (unidirectional-ascending); the movement on the face is unidirectional-plane, fixed on the chick; the indicated pressure is from halfpressure to full-pressure (unidirectional-discending), indicating an augmenting stronger pressure.

Bar two is characterized by a unidirectionnal-(discending) (from $\mathrm{E}_{5}$ to $\mathrm{H}_{4}$ ) and cyclic/centric motion, compared to the first bar, that finish on the $\mathrm{H}_{4}$, that is the central pitch of those first two measures. In fact, the musical profile is characterized by a small ornamentation around the final note. The dynamic is stable (the same of the previous bar), characterized in the third and fourth beat by a diminuendo (unidirectionnal-descending). The movement of the hand is plane (centric-pericentrality) while face movement is fixed on the forehead (cyclic/centric). The pressure is characterized by two opposite movements: in the second and fourth beat the prescribed movement is palm-fingertip (fast lightening of the pressure) (reciprocal-parabola like: from the palm to fingertip and vice-versa); the first and third are characterized by an "accent" movement with the palm, defined by a stronger pressure on the chick (centric/cyclic-plane: stable on the palm).

On bar three the musical score indicates a periodic iteration in the higher register around $\mathrm{D}_{5}$ and $\mathrm{E}_{5}$, thus defining an unidirectional-plane movement, ascending in the second part of the measure with a bi-chord $\mathrm{C}_{5}-\mathrm{E}_{5}, \mathrm{C}_{6}-\mathrm{E}_{5}$ (unidirectional-ascending movement). The dynamic profile is unidirectionalplane. The tactile score follows homo-rhytmically the music indicating a plane unidirectional movement, in the first part of the bar (first two beats). In the first two bars the movement on the face is fixed on the forehead (centric), moving towards the eyes on the semi-quaver (beat two) (unidirectional-descending) and on the downbeat of the third beat on the chin (unidirectionaldiscending). Thus the movement on the face defines a profile from the forehead to the chin passing through the eyes (it corresponds to a global reciprocal peri-centric movement from the chick to the chin). The movement on the surface of the hand is defined by a centric-plane movement, fixed on the palm. From the point of view of the pressure the movement is plane (first and second beat) and iterative-unidirectional (continuous movement from full to light pressure at each quaver of the last two beats).

The last bar of the phrase, is characterized by a cyclic/centric-cetrifugal motion, from the point of view of the melodic profile, and a unidirectional-descending dynamic profile. The tactile score indicates a 
movement on the face from the chicks (ciclic-rotation) to the chin through the neck, the forehead and the eyes (unidirectional-motion). This movement indicates a composite directionality that encompasses the whole face. The movement on the surface of the hand is reciprocal-parabola, between the palm and the proximal phalanges. Differently from the previous bars, the movement on the surface of the face and of the parts of the hand is correlated. The chick is massaged with the palm, the neck with the proximal phalange, the forehead with the palm and the chin with the proximal phalange. The pressure movement is cyclic-centric-rotation.

\begin{tabular}{|l|l|l|l|l|l|}
\hline $\begin{array}{l}\text { Movements } \\
\text { Bars }\end{array}$ & $\begin{array}{l}\text { Melodic } \\
\text { profile }\end{array}$ & $\begin{array}{l}\text { Dynamic } \\
\text { profile }\end{array}$ & $\begin{array}{l}\text { Hand } \\
\text { movement }\end{array}$ & $\begin{array}{l}\text { Face } \\
\text { movement }\end{array}$ & $\begin{array}{l}\text { Pressure } \\
\text { movement }\end{array}$ \\
\hline $\mathbf{1}$ & $\begin{array}{l}\text { reciprocal- } \\
\text { parabola }\end{array}$ & reciprocal-parabola & $\begin{array}{l}\text { unidirectional- } \\
\text { ascending }\end{array}$ & ciclic/centric & $\begin{array}{l}\text { unidirectional- } \\
\text { discending }\end{array}$ \\
\hline $\mathbf{2}$ & $\begin{array}{l}\text { unidirectionnal- } \\
\text { discending }\end{array}$ & $\begin{array}{l}\text { unidirectionnal- } \\
\text { descending }\end{array}$ & cyclic/centric & cyclic/centric & $\begin{array}{l}\text { reciprocal-parabola } \\
\text { centric/cyclic-plane }\end{array}$ \\
\hline $\mathbf{3}$ & $\begin{array}{l}\text { unidirectional- } \\
\text { plane }\end{array}$ & unidirectional-plane & centric-plane & reciprocal peri- \\
centric & unidirectional-plane \\
\hline $\mathbf{4}$ & $\begin{array}{l}\text { cyclic/centric- } \\
\text { cetrifugal }\end{array}$ & $\begin{array}{l}\text { unidirectional- } \\
\text { descending }\end{array}$ & $\begin{array}{l}\text { reciprocal- } \\
\text { parabola }\end{array}$ & $\begin{array}{l}\text { ciclic-rotation/ } \\
\text { unidirectional- } \\
\text { motion }\end{array}$ & cyclic-centric-rotation \\
\hline
\end{tabular}

The tactile and musical movements define a gestural-sonorous polyphony characterized by two clearly divided layers. The musical movements are defined by a fundamental inherent isomorphism, e.g. the first bar is characterized by a melodic and dynamic profile reciprocal-parabola. On the contrary the tactile movement of the first bar is heteromorphic. It is characterized by a hand movement unidirectionnal-ascending, a cyclic/centric face movement and a unidirectional-descending pressure. In the second bar the unidirectional movement of the sonorous movement is associated with cyclic/centric tactile movement; the third bar is characterized by a unidirectional-plane sonorous movement and a multifaceted tactile movement, defined by centric-plane hand movement, reciprocalperi-centric face movement and unidirectional-plane pressure. This polyphonic movement is characterize in the fourth bar by a cyclic/centric sonorous movement in the melodic profile and a unidirectional descending dynamic profile; the tactile object is characterized by a reciprocal-parabola hand movement; a cyclic/rotation unidirectional face movement and a cyclic/centric pressure.

This analysis shows the very complex relationship between the gestures used to produce tactile and acoustic experience. The sonorous objets and gestural objects are defined by a strong internal coherence. e.g. the sonorous objects are isomorphic from the point of view of the melodic and dynamic profile. They are characterized by similar movement typology: reciprocal, unidirectional etc. On the opposite gestural objects are defined by a kind of internal polyphony. e.g. hand movement unidirectional, face movement cyclic and unidirectional pressure; cyclic hand and face movement and reciprocal-parabola pressure. Massage's movements are characterized by a detailed differentiation 
caused, probably, by the extremely fine capability of our tactile sense to discriminate slightly different informations, that detect micro-changing in the massage texture. For that reason it is difficult to highlight constants among those two dimensions. However the proposed methodology allows to define the correlations between sonorous and gestural object and point, in the future, to define a class of gestural-sonorous objects.

\section{Conclusion and future developments}

This study allows to define gesture's notation as a common aspect of musical and tactile scores. Notation emerges as a graphical representation of gestures that are revealed as the central aspect of cognitive schemata capables to recode, trough gestural metaphors, the sensitive experience. In fact tactile experience is transposed in musical experience and vice-versa using gestures metaphors that transcode the informations in multiple modals outputs. Gesture prescription also appears as a central aspect of notation of temporal experience. Future developments are characterized by the improvement of the proposed analytical methodology and by the analysis of more case studies that could allow to have a bigger number of example to support the research in cognitive science, informatics and art. Finally the author, that is a music composer, think that, on this basis, it will be possible to realize new pieces starting from tactile scores. This artistic research path could be characterized by the definition of spectromorphological correlations between tactile and acoustic experience using Denis Smalley's theoretical framework to define the sound typologies of new musical pieces, especially in the domain of electroacoustic music.

\section{Bibliography}

Hermann, T., Hunt, A., Neuhoff, J.G., The Sonification Book, Berlin, Logos Publishing House, 2011.

Godoy, R.-I., “Gestural-Sonorous Objects: embodied extensions of Schaeffer's conceptual apparatus”, Organised Sound, vol.2, n², 2006, p. 149-156.

Launay, J., "Musical Sounds, Motor Resonance, and Detectable Agency", Empirical Musicology, vol. $10, n^{\circ} 1,2015$, p. 30-40.

Leman, M., Embodied Music Cognition and Mediation Technology, Cambridge, MIT Press, 2007.

Schaefer, R.S., "Mental Representations in Musical Processing and their Role in Action-Perception Loops”, Empirical Musicology, vol. 9, n³-4, 2014, p. 161-176.

Schaeffer, P., Traité des objets musicaux. Essai Interdisciplinaires, Paris, Editions du Seuil, 1966.

Smalley, D., "Spectromorphology: explaining sound-shapes", Organised Sound, vol. 2, 1997, p. 10726.

Suzuki, Y., Suzuki, R., Tactile Score. A Knowledge Media for Tactile Sense, Tokyo, Springer, 2014. 
